\title{
ER-2 High Altitude Solar Cell Calibration Flights
}

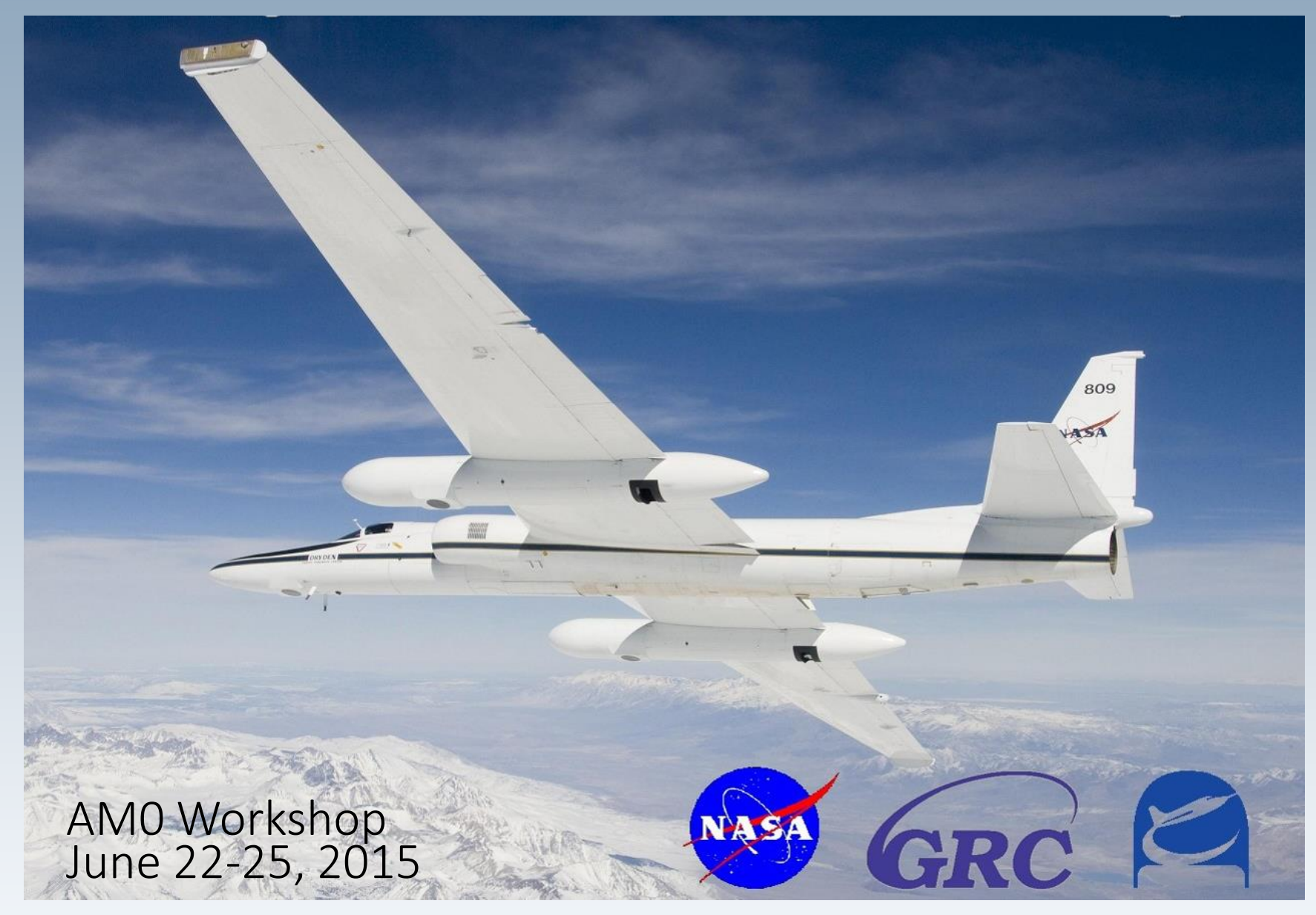

Matthew G. Myers and Michael F. Piszczor

Photovoltaic and Electrochemical Systems Branch 


\section{Test Platform Overview}

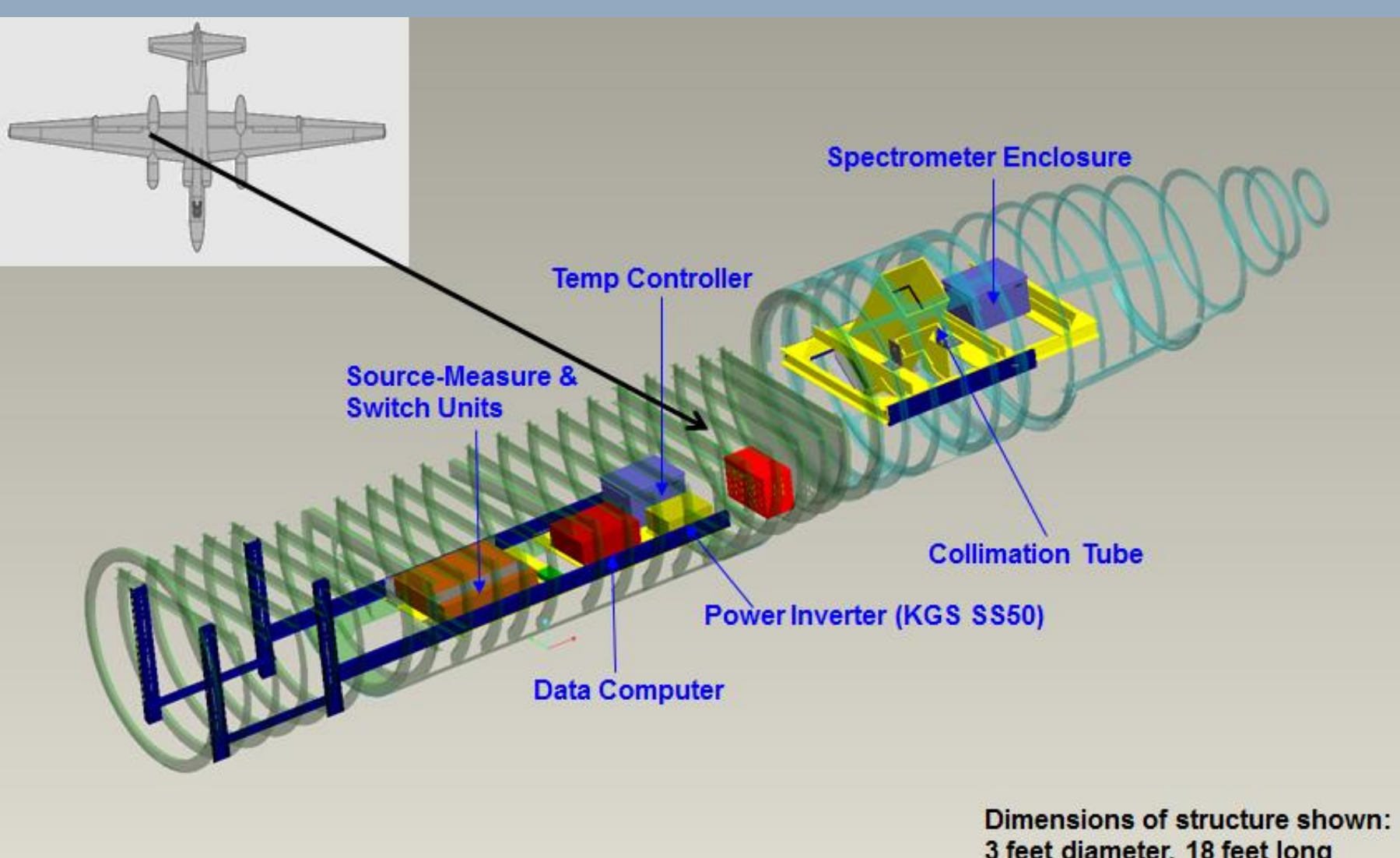

\section{Demonstrated Capabilities}

Altitude: $70,000 \mathrm{ft}+$

Illuminated Area: $5.6 \times 5.6$ inches

Pointing Accuracy: $<2^{\circ}$ deviation Temperature Control: (+/-) $0.5^{\circ} \mathrm{C}$

Number of devices per flight: 12 Maximum Cell Measurements: Isc, Voc, IV Curve Fiber-optic Port for spectrometer or other sensor Flight Season: April through September

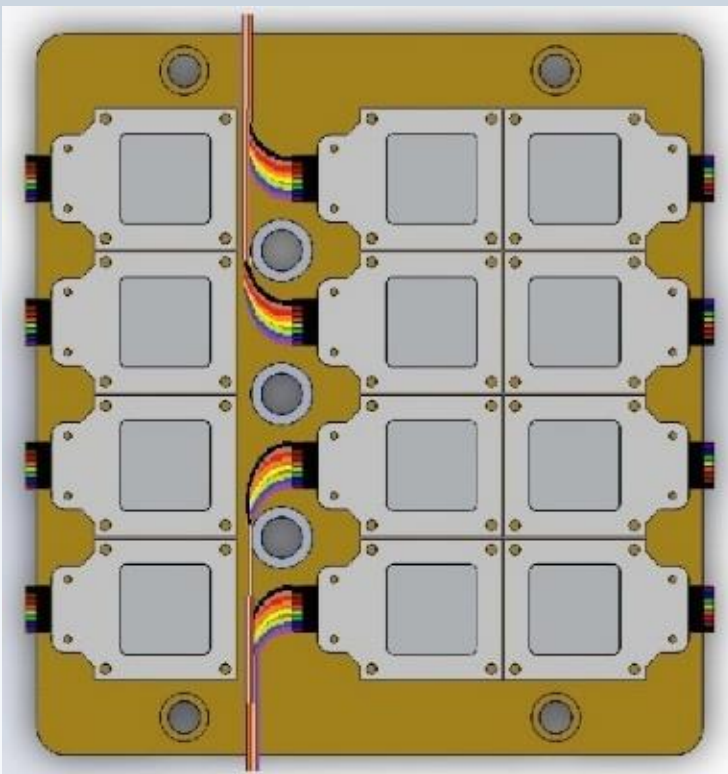

\section{Instruments Flown}

Keithley 2425 Source/Measure Unit

Ocean Optics HR2000+ Spectrometer

Ocean Optics NIRQuest NQ512-1.9 Spectrometer 


\section{Equipment}
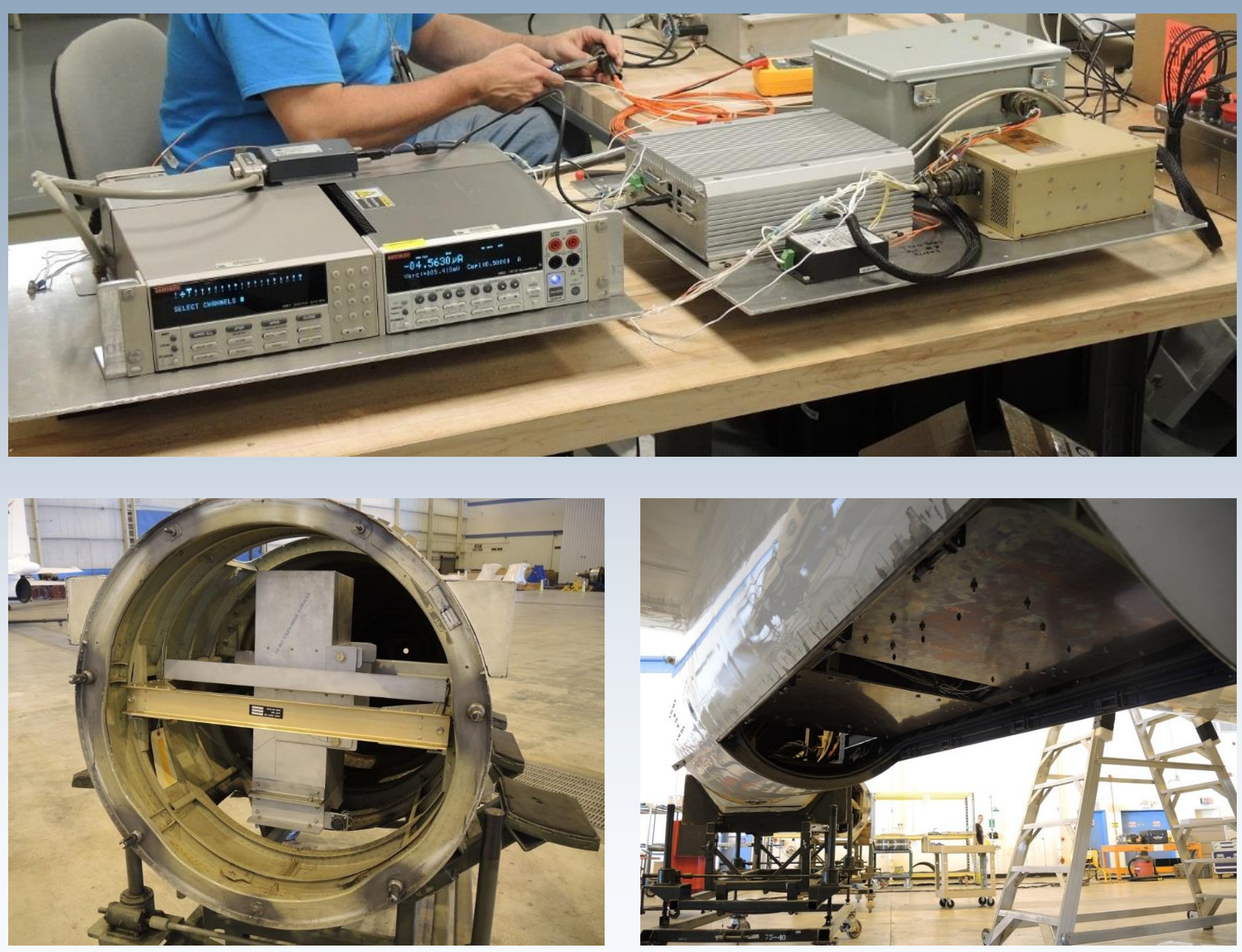


\section{Flight Profile}

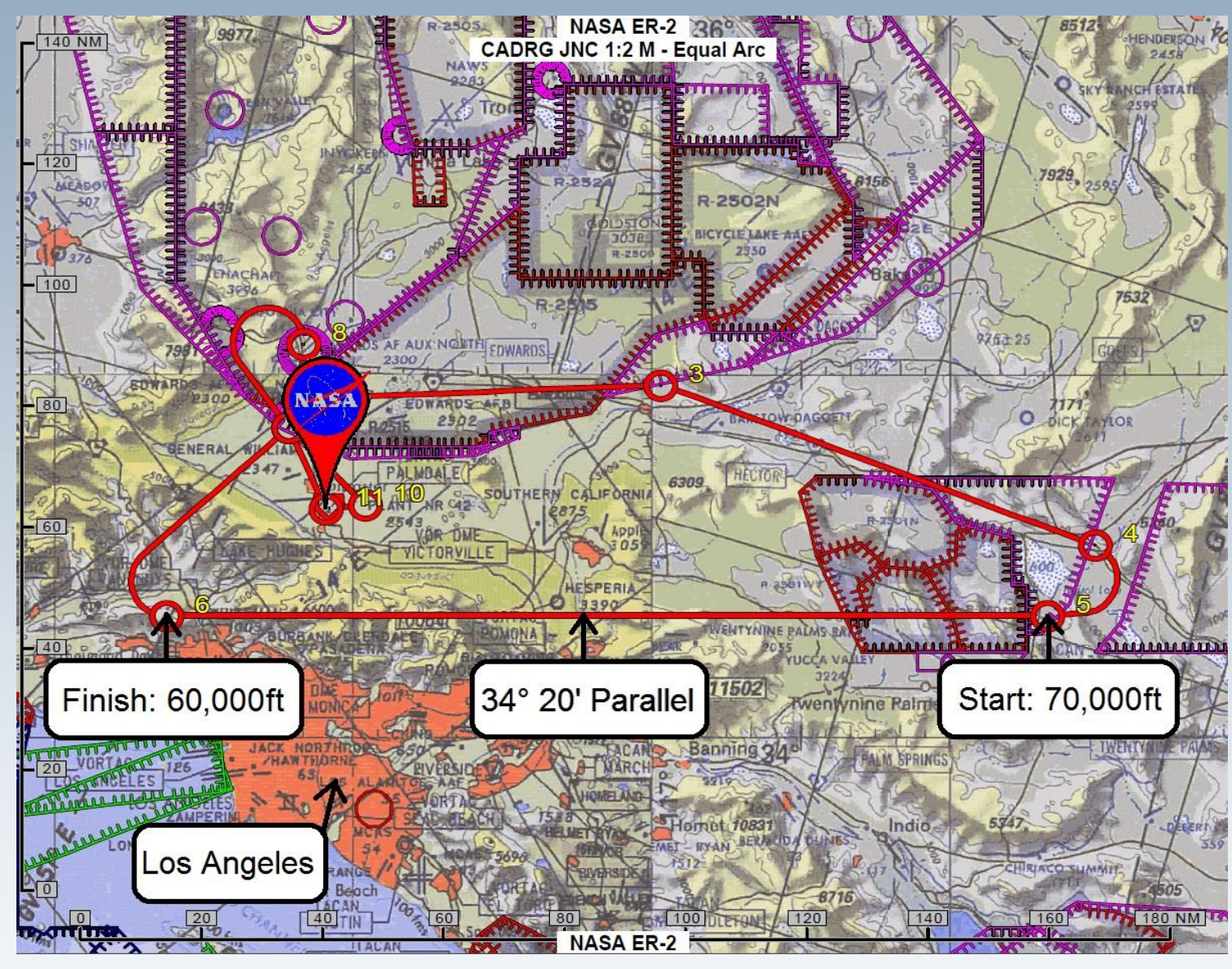

Ideal Regular Season Flight Path

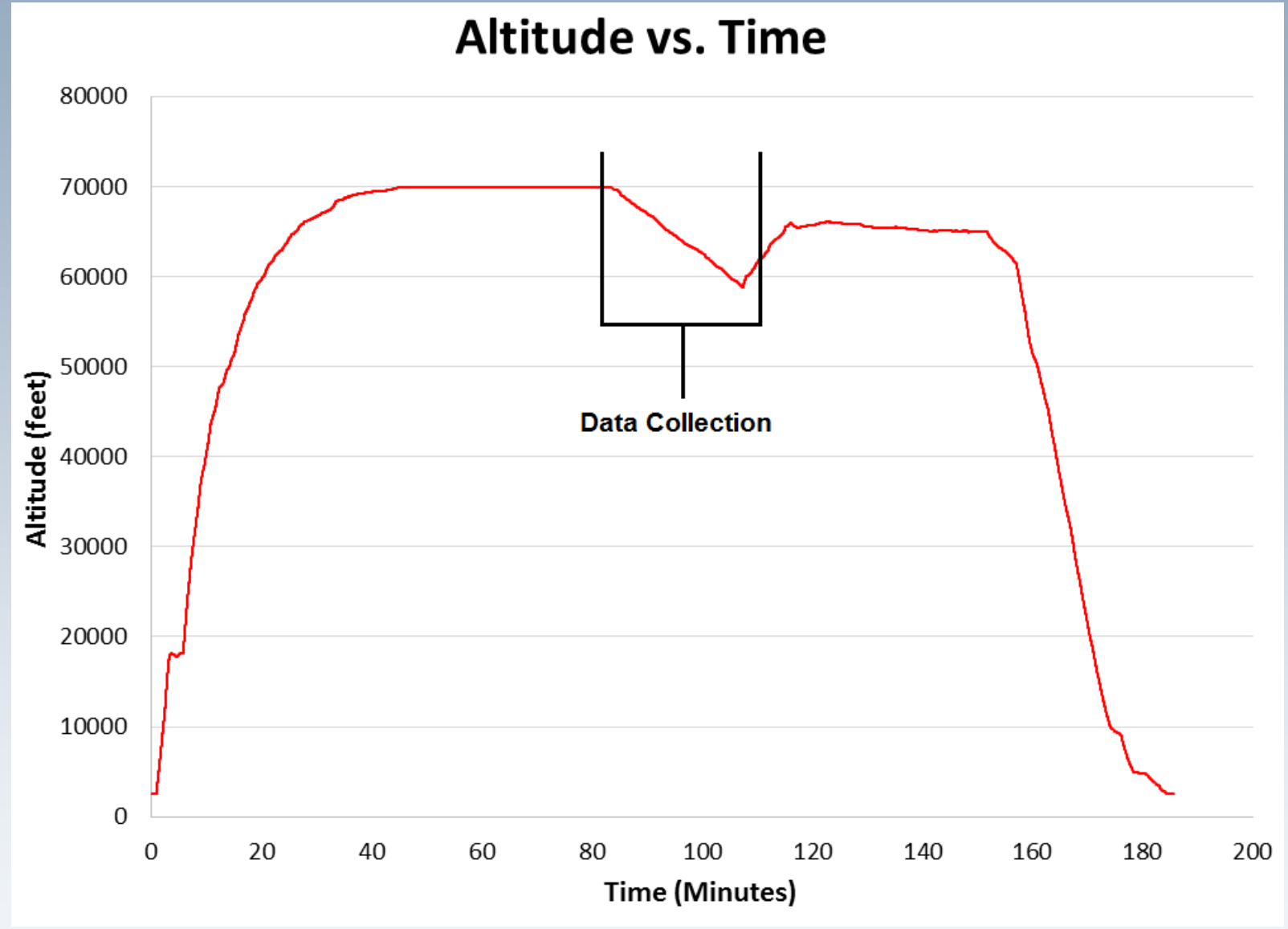

Actual Altitude Profile 


\section{Langley plot method}

1. Estimate ozone above cell using tables from appendix $A$ in publication:

"Earth Probe Total Ozone Mapping Spectrometer (TOMS) Data Products User's Guide"

\begin{tabular}{|c|c|c|c|c|c|c|c|c|c|c|c|}
\hline \multirow[b]{2}{*}{ Profile } & \multicolumn{10}{|c|}{ Umkehr Layer Number } & \\
\hline & 0 & 1 & 2 & 3 & 4 & 5 & 6 & 7 & 8 & 9 & $>9$ \\
\hline $225 \mathrm{~L}$ & 15.0 & 9.0 & 5.0 & 7.0 & 25.0 & 62.2 & 57.0 & 29.4 & 10.9 & 3.2 & 1.3 \\
\hline $275 \mathrm{~L}$ & 15.0 & 9.0 & 6.0 & 12.0 & 52.0 & 79.2 & 57.0 & 29.4 & 10.9 & 3.2 & 1.3 \\
\hline $325 \mathrm{~L}$ & 15.0 & 9.0 & 10.0 & 31.0 & 71.0 & 87.2 & 57.0 & 29.4 & 10.9 & 3.2 & 1.3 \\
\hline $375 \mathrm{~L}$ & 15.0 & 9.0 & 21.0 & 53.0 & 88.0 & 87.2 & 57.0 & 29.4 & 10.9 & 3.2 & 1.3 \\
\hline $425 \mathrm{~L}$ & 15.0 & 9.0 & 37.0 & 81.0 & 94.0 & 87.2 & 57.0 & 29.4 & 10.9 & 3.2 & 1.3 \\
\hline $475 \mathrm{~L}$ & 15.0 & 9.0 & 54.0 & 108.0 & 100.0 & 87.2 & 57.0 & 29.4 & 10.9 & 3.2 & 1.3 \\
\hline $125 \mathrm{M}$ & 6.0 & 5.0 & 4.0 & 6.0 & 8.0 & 31.8 & 28.0 & 20.0 & 11.1 & 3.7 & 1.4 \\
\hline $175 \mathrm{M}$ & 8.0 & 7.0 & 8.0 & 12.0 & 26.0 & 41.9 & 33.6 & 22.3 & 11.1 & 3.7 & 1.4 \\
\hline $225 \mathrm{M}$ & 10.0 & 9.0 & 12.0 & 18.0 & 44.0 & 52.1 & 39.2 & 24.5 & 11.1 & 3.7 & 1.4 \\
\hline $275 \mathrm{M}$ & 16.0 & 12.0 & 15.0 & 29.0 & 58.0 & 63.7 & 40.6 & 24.5 & 11.1 & 3.7 & 1.4 \\
\hline $325 \mathrm{M}$ & 16.0 & 14.0 & 26.0 & 45.0 & 74.7 & 66.9 & 41.7 & 24.5 & 11.1 & 3.7 & 1.4 \\
\hline $375 \mathrm{M}$ & 16.0 & 16.0 & 39.0 & 64.0 & 85.7 & 71.1 & 42.5 & 24.5 & 11.1 & 3.7 & 1.4 \\
\hline $425 \mathrm{M}$ & 16.0 & 18.0 & 54.0 & 84.0 & 97.7 & 71.7 & 42.9 & 24.5 & 11.1 & 3.7 & 1.4 \\
\hline $475 \mathrm{M}$ & 16.0 & 22.0 & 72.0 & 107.7 & 101.0 & 72.6 & 43.0 & 24.5 & 11.1 & 3.7 & 1.4 \\
\hline $525 \mathrm{M}$ & 16.0 & 26.0 & 91.0 & 127.7 & 108.0 & 72.6 & 43.0 & 24.5 & 11.1 & 3.7 & 1.4 \\
\hline $575 \mathrm{M}$ & 16.0 & 30.0 & 110.0 & 147.7 & 115.0 & 72.6 & 43.0 & 24.5 & 11.1 & 3.7 & 1.4 \\
\hline $125 \mathrm{H}$ & 9.5 & 7.0 & 18.3 & 7.6 & 8.2 & 28.6 & 22.0 & 12.4 & 7.7 & 2.5 & 1.2 \\
\hline $175 \mathrm{H}$ & 9.5 & 8.0 & 22.8 & 22.0 & 26.9 & 32.3 & 26.8 & 15.0 & 8.0 & 2.5 & 1.2 \\
\hline $225 \mathrm{H}$ & 10.0 & 9.0 & 27.6 & 45.7 & 41.0 & 35.0 & 28.8 & 15.4 & 8.3 & 2.9 & 1.3 \\
\hline $\begin{array}{l}275 \mathrm{H} \\
325 \mathrm{H}\end{array}$ & $\begin{array}{l}14.0 \\
14.0\end{array}$ & $\begin{array}{l}12.0 \\
15.0\end{array}$ & $\begin{array}{l}34.0 \\
46.8\end{array}$ & $\begin{array}{l}66.9 \\
82.6\end{array}$ & $\begin{array}{l}54.2 \\
65.2\end{array}$ & $\begin{array}{l}36.0 \\
41.7\end{array}$ & $\begin{array}{l}28.8 \\
28.8\end{array}$ & \multirow{3}{*}{\multicolumn{2}{|c|}{$\begin{array}{c}\text { Umkehr } \\
\text { Level }\end{array}$}} & \multirow{2}{*}{\multicolumn{2}{|c|}{$\begin{array}{c}\text { Ozone above top of level (DU) } \\
\text { for specified total column }\end{array}$}} \\
\hline $375 \mathrm{H}$ & 14.0 & 20.0 & 61.2 & 93.8 & 75.2 & 45.9 & 32.5 & & & & \\
\hline $425 \mathrm{H}$ & 14.0 & 25.0 & 76.2 & 104.9 & 84.2 & 51.4 & 35.6 & & & \multicolumn{2}{|r|}{290} \\
\hline $475 \mathrm{H}$ & 14.0 & 32.0 & 91.0 & 117.1 & 93.0 & 55.8 & $\begin{array}{l}37.5 \\
38.2\end{array}$ & \multicolumn{2}{|c|}{ Ground } & & 290.00 \\
\hline $\begin{aligned} 525 \mathrm{H} \\
575 \mathrm{H}\end{aligned}$ & 14.0 & 41.0 & 107.1 & 128.1 & 101.0 & 60.2 & $\begin{array}{l}38.2 \\
38.8\end{array}$ & \multirow{2}{*}{\multicolumn{2}{|c|}{0}} & & 275.53 \\
\hline $575 \mathrm{H}$ & 14.0 & 49.0 & 123.2 & 142.2 & 111.0 & 60.6 & 38.8 & \multirow{2}{*}{\multicolumn{2}{|c|}{1}} & \multicolumn{2}{|r|}{264.86} \\
\hline & & & & & & & & \multirow{2}{*}{\multicolumn{2}{|c|}{2}} & \multicolumn{2}{|r|}{251.72} \\
\hline & & & & & & & & & & \multirow{2}{*}{\multicolumn{2}{|c|}{224.65}} \\
\hline & & & & & & & & \multicolumn{2}{|r|}{3} & \multirow{2}{*}{\multicolumn{2}{|c|}{163.79}} \\
\hline & & & & & & & & \multicolumn{2}{|r|}{4} & & \\
\hline & & & & & & & & \multicolumn{2}{|r|}{5} & \multicolumn{2}{|r|}{90.39} \\
\hline
\end{tabular}

a.) Linearly Interpolate ozone distribution data to flight latitude

b.) Find polynomial fits of ozone in given levels as a function of total ozone column

c.) Use data from the Ozone Monitoring Instrument (OMI) on board the Aura spacecraft to determine total ozone column at the time and location of the flight

d.) Use ozone layer distribution model to interpolate and estimate of the ozone above the cell for each data point taken as the aircraft descends 


\section{Langley plot method}

\section{Generate Langley Plot}

a.) Correct each Isc data point for overhead ozone, ozone sensitivity coefficient, and sun elevation angle

b.) Plot log of ozone-corrected Isc vs airmass (pressure over sine of elevation angle

c.) Extrapolate linear fit of plot to zero airmass and estimate AMO Isc

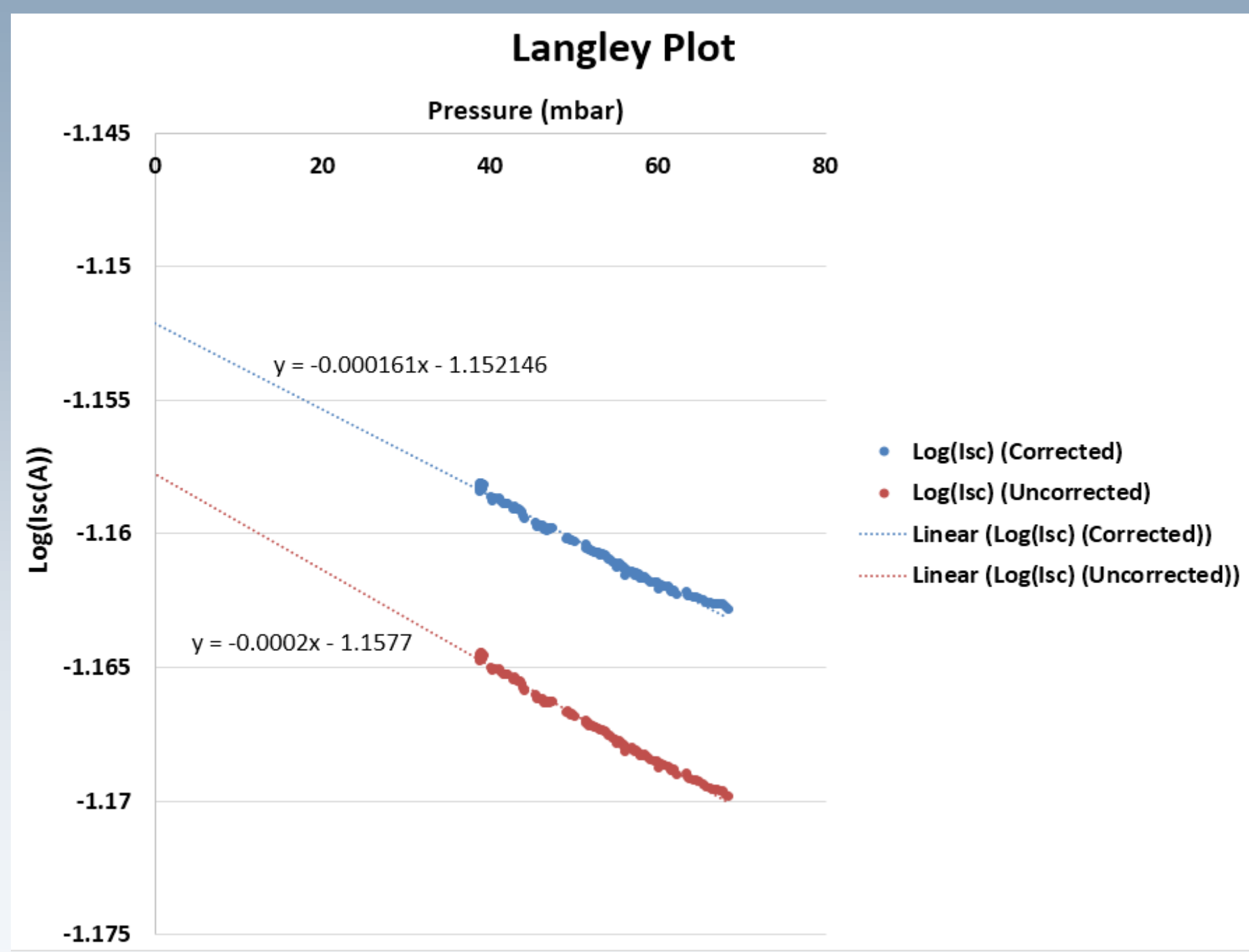

Langley Plot shown for GRC ZTJ 2x2cm top cell flown October $10^{\text {th }} 2014$ 


\section{Summary of First ER-2 Campaign}

- Three flights were flown between October $8^{\text {th }}$ and October $14^{\text {th }}, 2014$

- Data was taken between 55,000 and 70,000 feet

- The first flight consisted of six $2 \times 2 \mathrm{~cm}$ cells and a camera to observe plate illumination conditions

- The second and third flights consisted of twelve $2 \times 2 \mathrm{~cm}$ cells

- All flights carried two sun sensors and two Ocean Optics spectrometers

- A ZTJ top and middle $2 \times 2 \mathrm{~cm}$ sub cell which were previously flown on the Learjet were flown all three flights

- Thirteen other cells were flown at least once

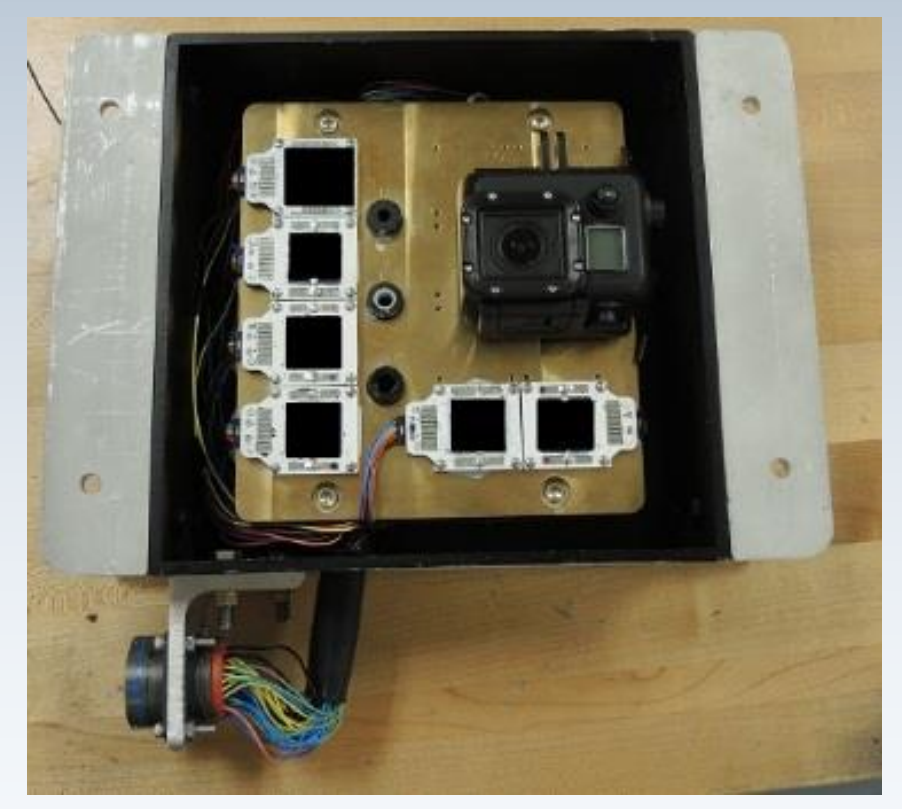

First flight stage plate configuration

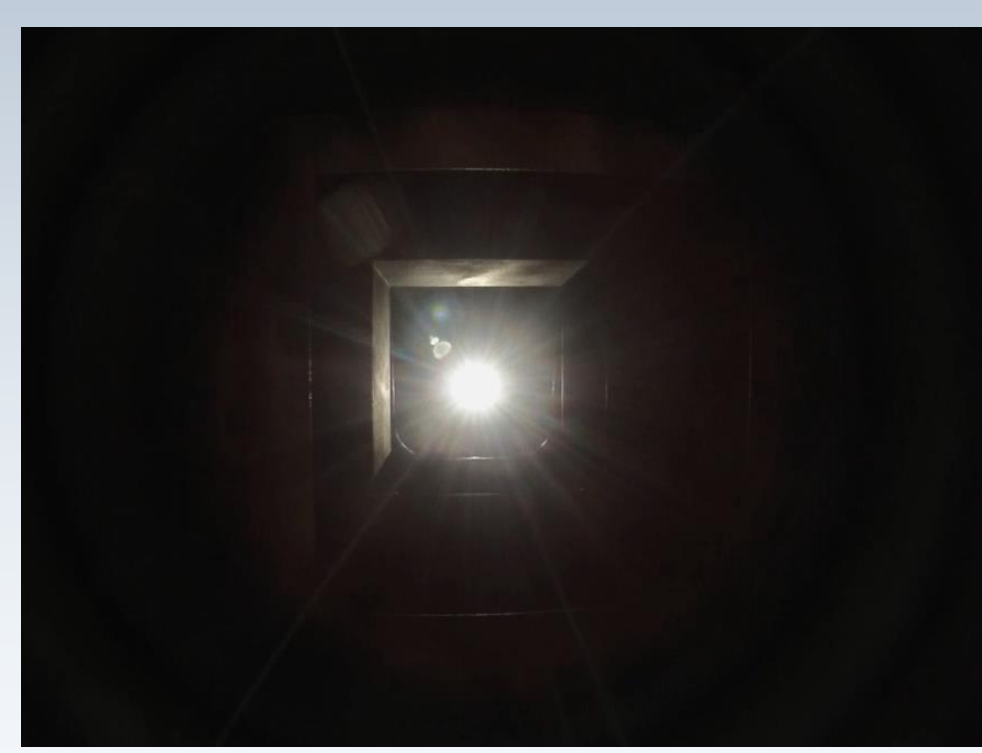

View of sun from stage plate

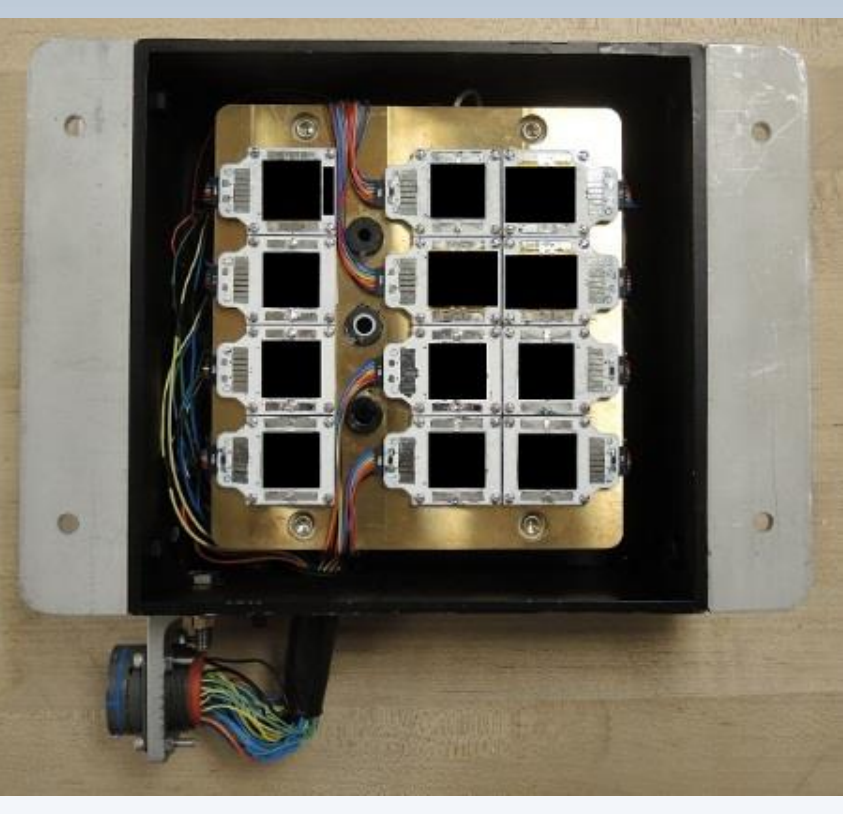

Second and Third flight stage plate configuration 
ER-2 Takeoff and Landing 


\section{Corrected Isc Results}

\section{Full Data Set}

\begin{tabular}{|c|c|c|c|}
\hline Cell & TC0108 & MC0907 & TC0109 \\
\hline Flight One & 69.925 & 66.004 & 70.096 \\
\hline Flight Two & 70.232 & 66.063 & \\
\hline Flight Three & 70.289 & 65.990 & \\
\hline Average & 70.149 & 66.019 & 70.096 \\
\hline Std Dev & 0.196 & 0.039 & \\
\hline Covar \% & 0.279 & 0.059 & \\
\hline Learjet Value & 70.510 & 66.230 & 70.51 \\
\hline Lear Variance (\%) & 0.512 & 0.319 & 0.587 \\
\hline
\end{tabular}

\section{$<60 m b$ Data Only}

\begin{tabular}{|c|c|c|c|}
\hline Cell & TC0108 & MC0907 & TC0109 \\
\hline Flight One & 70.339 & 65.995 & 70.576 \\
\hline Flight Two & 70.325 & 66.069 & \\
\hline Flight Three & 70.289 & 65.990 & \\
\hline Average & 70.318 & 66.018 & 70.576 \\
\hline Std Dev & 0.026 & 0.044 & \\
\hline Covar \% & 0.037 & 0.067 & \\
\hline Learjet Value & 70.51 & 66.23 & 70.51 \\
\hline Lear Variance (\%) & 0.27 & 0.32 & -0.09 \\
\hline
\end{tabular}

- Data shown for GRC $2 \times 2 \mathrm{~cm}$ ZTJ sub cells (two top cells and one middle)

- Ozone corrections based on established Learjet methods

- Further atmospheric correction methods are being investigated

- SMARTS or other ozone models

- Using only higher altitude data

- Ozone correction coefficients using cell EQE data 


\section{Curve Examples}

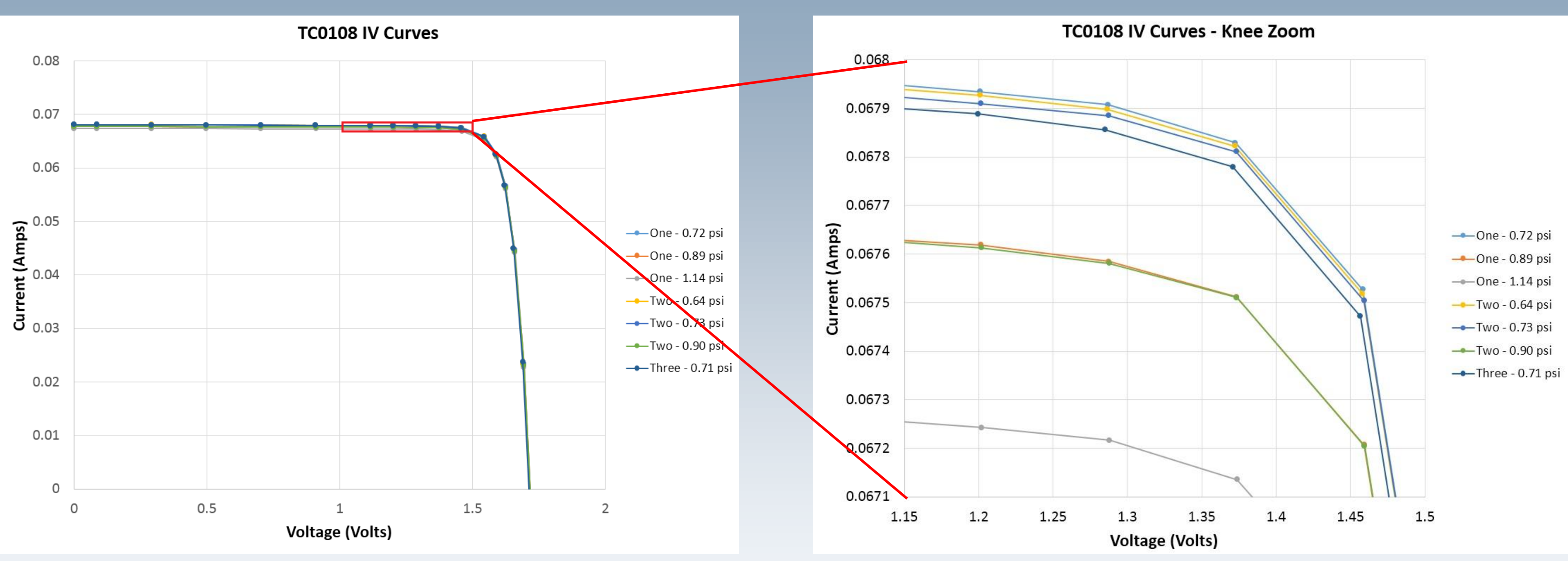

IV Curves show good repeatability over multiple flights and a predictable change with pressure 


\section{Solar Spectra}

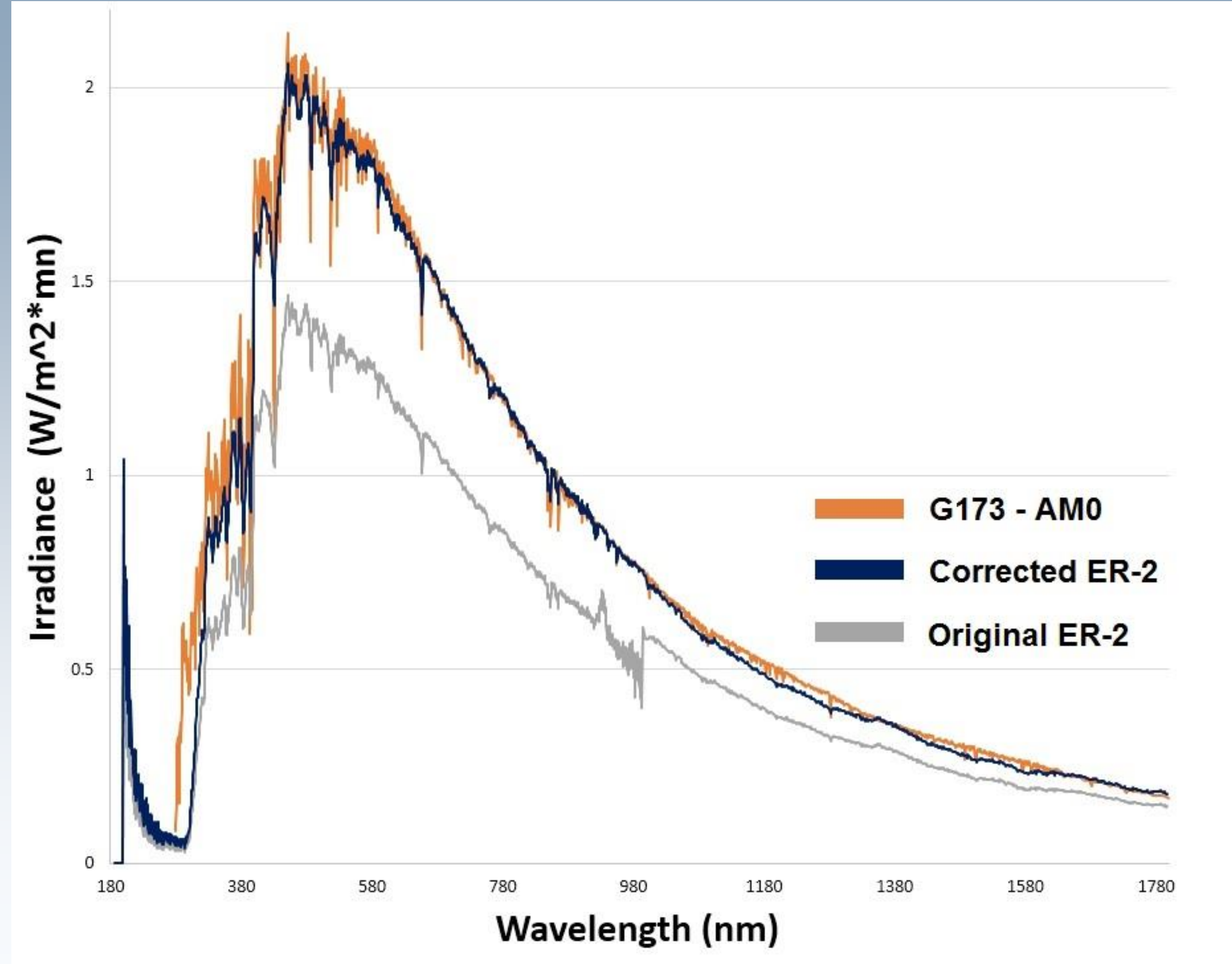




\section{Device Temperature Control}

- Mounting Plate temperature is used for heater feedback control

- All cell temperatures are monitored independently using AD590 IC temperature transducers

- After a slight bump caused by initial solar illumination, all cell temperatures were maintained within approximately $0.25^{\circ} \mathrm{C}$ from the target of $25^{\circ} \mathrm{C}$

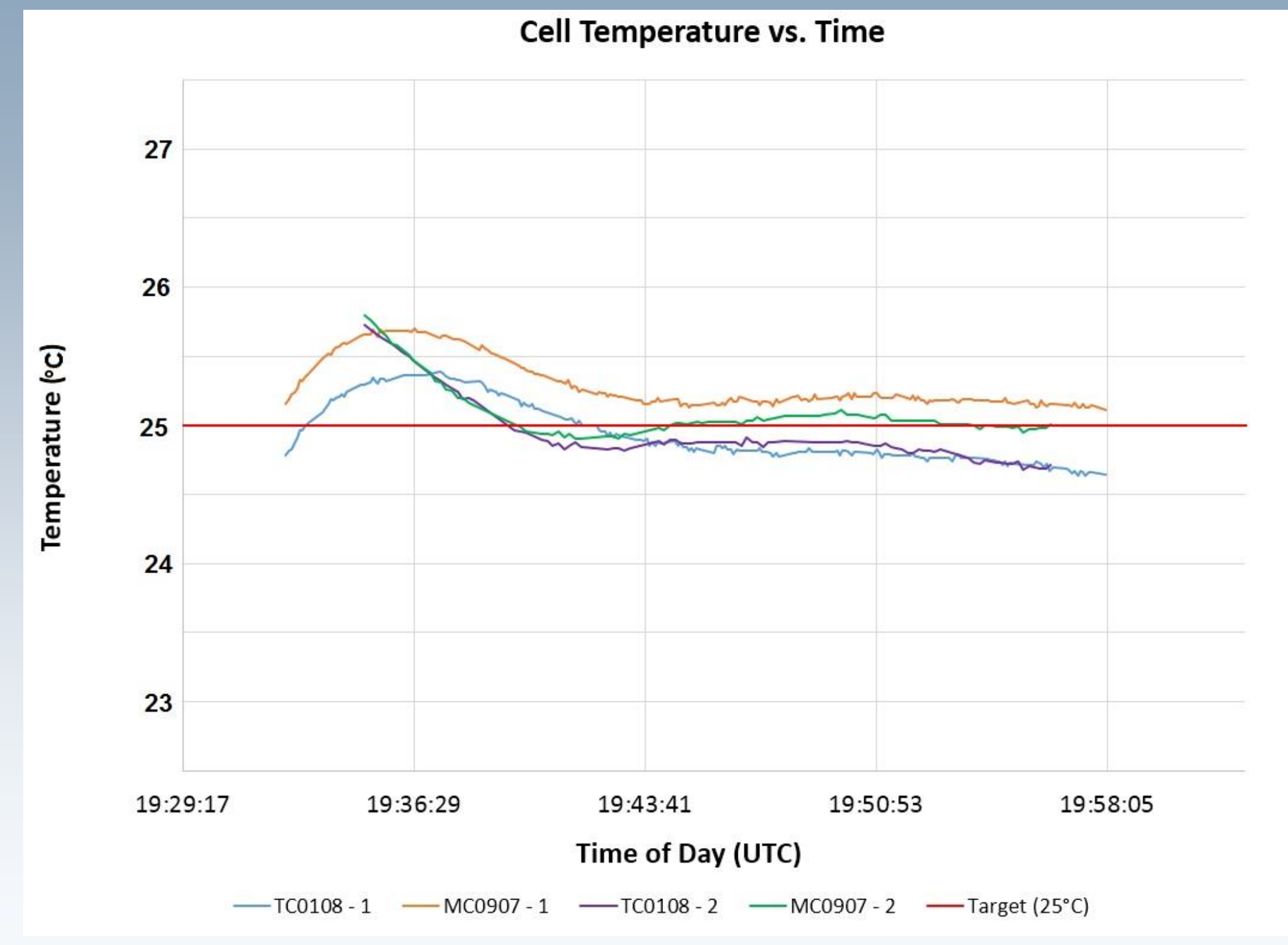

- Variation of temperature for any individual cell was on the order of $0.1^{\circ} \mathrm{C}$ after the initial on-sun disturbance 
Sun Pointing 


\section{Summary of ER-2 Capability}

- Flights can be conducted once every one to two days during a campaign

- Flight season runs from April through September

- Twelve $2 \times 2 \mathrm{~cm}$ cells can be flown per flight, or any other configuration that fits inside of the $14.2 \times 14.2 \mathrm{~cm}$ illuminated area

- This capacity could be doubled if the second ER-2 pod is used

- Data supplied includes Isc, Voc, IV curve, and cell temperature

- Other optical or atmospheric sensors can be flown as able 
Recent Results on Solar Cell Experiment on ISS
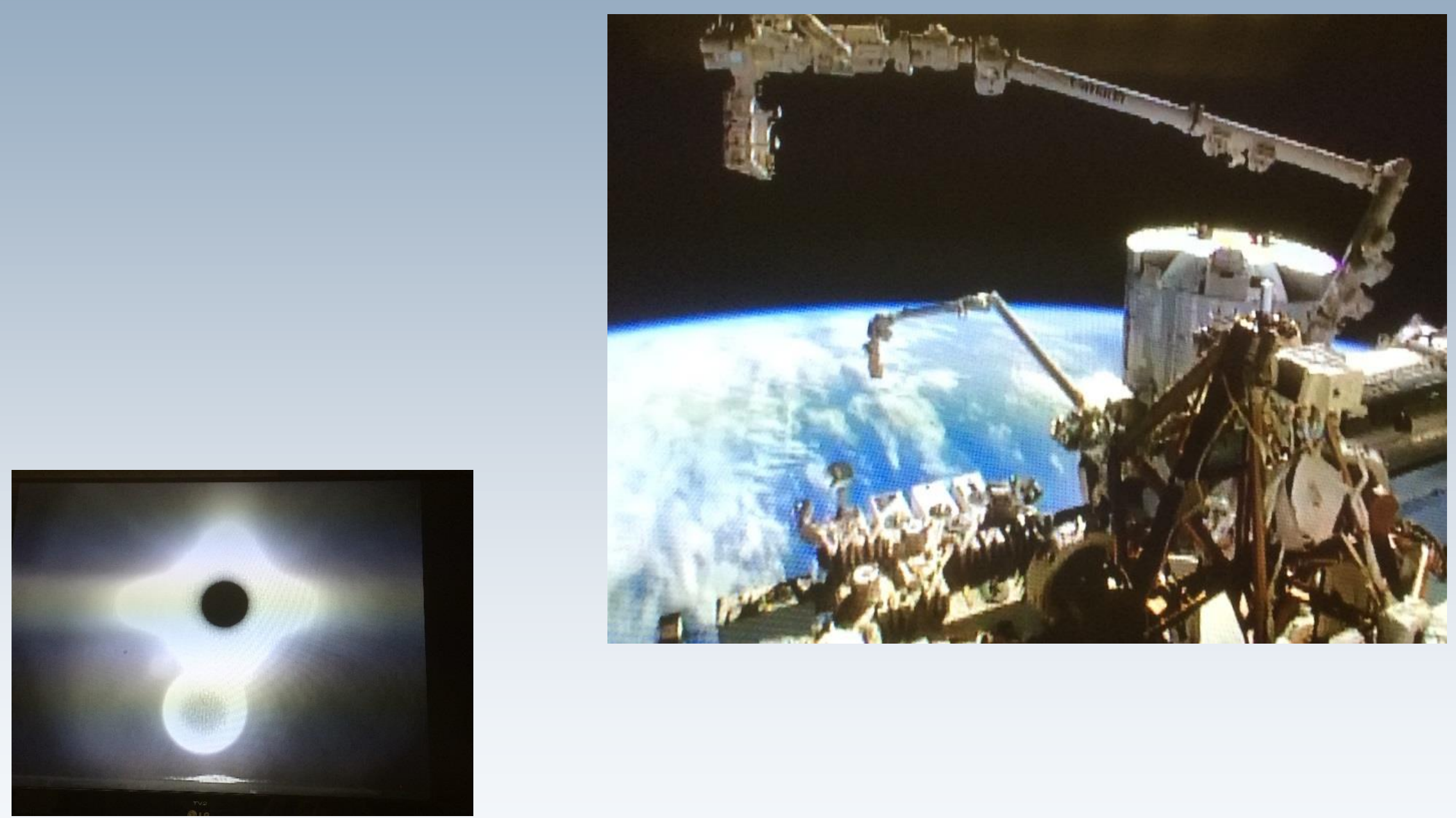


\section{GRC/AFRC ER-2 Flight Campaign for Creating Air Mass Zero (AMO) Primary Calibration Standards}

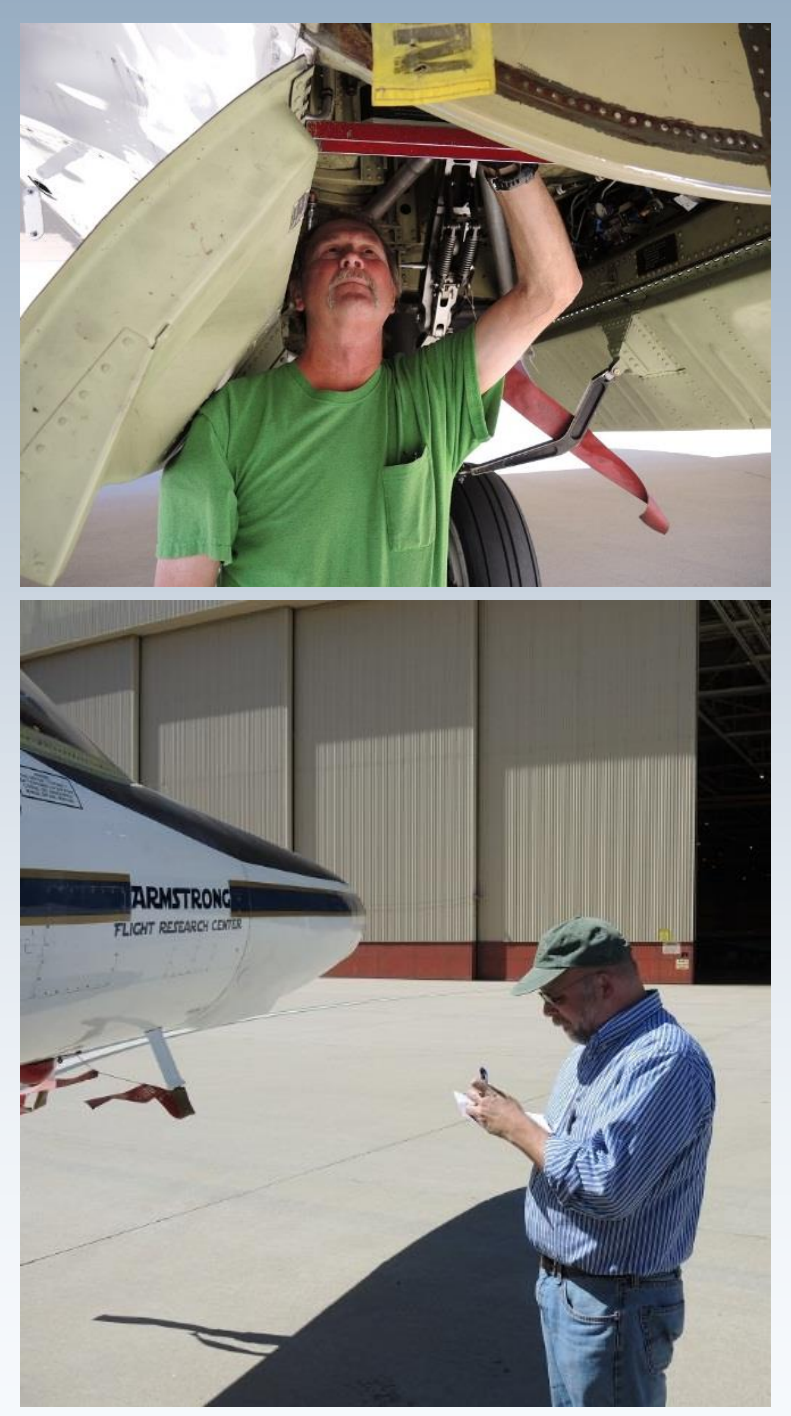

- GRC announcement sent out the week of May 4, 2015

- New platform supplements the Learjet AMO calibration capability

- GRC Learjet flight season January-March

- DFRC ER-2 flight season April - September

- Current 2015 ER-2 Flight Campaign:

- July 6th - 20th, 2015
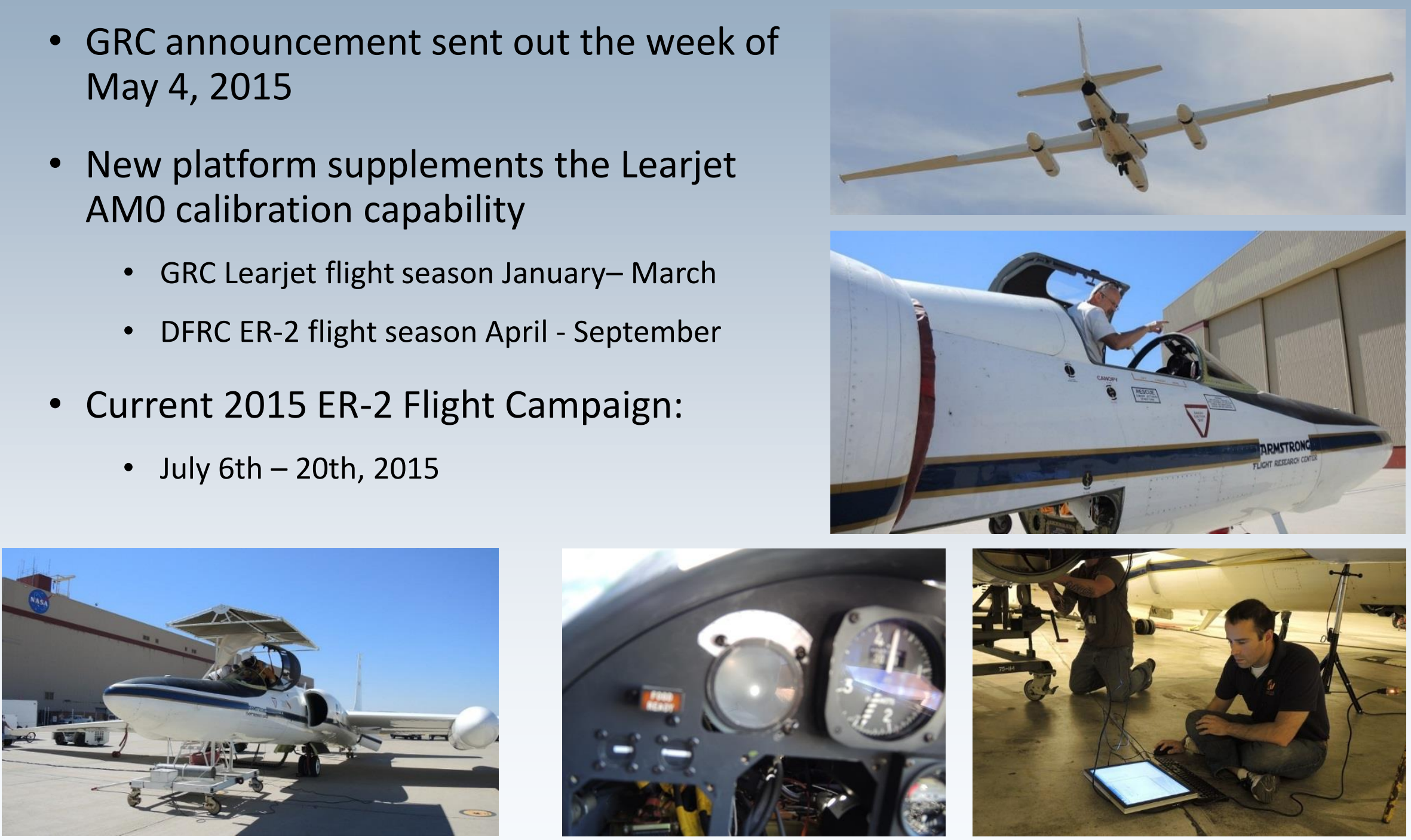